\title{
Galectin-8 Modulates Innate and Adaptive Immune Response Genes in Bovine Neutrophils
}

\author{
Eboghoye Eluka-Okoludoh ${ }^{1}$, Kingsley Ekwemalor ${ }^{1}$, Sarah Adjei-Fremah ${ }^{2}$, Bharath Mulakala ${ }^{2}$ \\ \& Mulumebet Worku ${ }^{2}$ \\ ${ }^{1}$ Department of Applied Science and Technology, North Carolina Agricultural and Technical State University, \\ USA \\ ${ }^{2}$ Department of Animal Sciences, North Carolina Agricultural and Technical State University, USA \\ Correspondence: Mulumebet Worku, Department of Animal Sciences, North Carolina A\&T State University, \\ Greensboro, NC, USA. E-mail: worku@ncat.edu
}

Received: December 19, 2018

Accepted: December 31, 2018

Online Published: January 29, 2019

doi:10.5539/jmbr.v9n1p24

URL: https://doi.org/10.5539/jmbr.v9n1p24

\begin{abstract}
Galectins (Gals) are a family of animal lectins that bind $\beta$-galactosides through a carbohydrate recognition domain. Galectin- 8 is a tandem-repeat galectin, secreted intracellularly and extracellularly. It is associated with neutrophil migration and has been studied as a possible therapeutic to combat inflammation. The objective of this study was to evaluate the translational and the transcriptional effects of recombinant Galectin-8 (rGal-8) on cow neutrophils. Blood was collected aseptically from Holstein-Friesian cows $(n=10)$ from the North Carolina A\&T State University Dairy Unit. Neutrophils isolated were treated with rGal-8 $(2 \mu \mathrm{g})$, or PBS (control) and were incubated at $37^{\circ} \mathrm{C}, 5 \% \mathrm{CO}_{2}$ for 1 hour. Supernatant from treated neutrophils was evaluated for total protein concentration, and galectin-8 secretion using bovine Galectin-8 Enzyme Linked-Immuno-Sorbent Assay (ELISA) kit. Total RNA was extracted, reverse transcribed, and RT-qPCR was performed using the RT $^{2}$ Profiler Cow Innate \& Adaptive Immune Responses Array with 84 genes. The Livak method was used to calculate transcript abundance and fold change ( $\mathrm{FC}>2$ considered significant). Total protein concentration increased $(\mathrm{P}=0.0361)$ after rGal-8 treatment compared to the untreated control. Galectin-8 secretion was not significantly different in control compared to treated group ( $\mathrm{P}=0.5819)$. Out of the 84 genes, 81 genes were differentially expressed in response to rGal-8; 14 up-regulated, 5 down-regulated, 61 genes remained unchanged. Treatment with rGal8 induced the expression of IRF7. The top five up-regulated genes include FAS, CD40, CD86, IFNGR1, STAT1; down-regulated genes were TLR9, CD14, CCR6, TICAM1, and TLR1. Selected genes were probed to validate fold change; the levels of gene expression were comparable to data from $\mathrm{RT}^{2}$ array. Exposure of bovine neutrophils to rGal-8 modified expression of immune response genes. The functional significance of the change needs further studies.
\end{abstract}

Keywords: Galectin-8, cow, neutrophils, immune

\section{Introduction}

The innate immune system, primarily leukocytes, serve as the first line of host defense and plays a crucial role in early recognition and pro-inflammatory response (Medzhitov \& Janeway, 2000). Neutrophil are primary leukocytes characterized by a polymorphic-segmented nucleus, contain numerous cytoplasmic granules, and large stores of glycogen for energy (Paape, Bannerman, Zhao, \& Lee, 2003). Numerous receptors are present on the neutrophil surface, some of these receptors detect chemoattractants that allow neutrophils to migrate toward areas of inflammation (Paape et al., 2003). Bovine neutrophils are comparable to neutrophils of other species in their functionality, activation mechanisms, diapedesis, and modulation of immune response (Bassel \& Caswell, 2018). The balance between microbial killing and host tissue damage is linked to neutrophil biochemical composition which is species specific (Bassel \& Caswell, 2018).

Galectin- 8 is a mammalian lectin, made of two carbohydrate-recognition domains in the same polypeptide chain, joined by a link peptide (Hadari et al., 1995). Galectins have been shown to modulate the innate and adaptive immune system (Rabinovich \& Gruppi, 2005; Vasta et al., 1994). Galectin expression and modulation in ruminants have been well- studied and reported previously (Eluka-Okoludoh et al., 2018; Ekwemalor et al., 2018; Asiamah et al., 2018; Osei et al., 2017, 2018; Mulakala et al., 2018). Galectin-8 acts as an extracellular matrix (ECM) protein that positively or negatively regulates cell adhesion, depending on the extracellular context and cell surface 
counter-receptors like integrins (Troncoso et al., 2014). Galectin-8 involvement in the migration or activation of inflammatory cells suggests a role in the pathogenesis of inflammatory diseases (Tribulatti, Cattaneo, Hellman, Mucci, \& Campetella, 2009). Galectin-8 modulates the neutrophil function via superoxide production (Nishi et al., 2003). The transcriptional and translational effects of Galectin- 8 in bovine neutrophils is not well understood. The objective of this study was to evaluate the effect of recombinant Galectin-8 (rGal-8) on transcription and translation of genes associated with immunity in cow neutrophils.

\section{Materials and Methods}

\subsection{Sample Collection}

Ten clinically healthy Holstein Friesian dairy cows from the North Carolina Agricultural and Technical State University (NC A\&T) Dairy Unit were used for this study. This study was approved by the Institutional Animal Care and Use Committee. Whole blood samples $(50 \mathrm{~mL})$ were collected from the jugular vein aseptically into tubes containing the anticoagulant citrate dextrose (ACD). Blood samples were processed within 2 hours of collection.

\subsection{Neutrophil Isolation Analysis}

Neutrophils were isolated from whole blood $(50 \mathrm{~mL})$ using the modified Carlson and Kaneko method (Carlson \& Kaneko, 1973). Whole blood was centrifuged on a swinging bucket rotor (Eppendorf Centrifuge $5810 \mathrm{R}$ ) at 1800 $\mathrm{x} \mathrm{g}$ at $4^{\circ} \mathrm{C}$ for 20 minutes. Isolated total cell count and viability was assessed using TC-20 (Bio-Rad), White blood cell differential count was calculated as described previously (Worku et al., 2016; Adjei-Fremah et al., 2016, 2018; Ekwemalor et al., 2016, 2018).

\subsection{Preparation of Treatments}

Recombinant human galectin-8 (source: E. coli, Novo protein, Summit, NJ), was reconstituted in endotoxin-free ultra-pure water (Invitrogen). Neutrophils $\left(10^{6}\right.$ cells $/ \mathrm{ml}$, viable cells) were treated with $2 \mu \mathrm{g} / \mathrm{ml} \mathrm{rGal}-8$ in PBS (PH 7.4), and untreated control samples were maintained in Phosphate buffer saline (PBS) served as control. All reagents used were endotoxin-free as tested with the ToxinSensor ${ }^{\mathrm{TM}}$ Chromogenic LAL Endotoxin Assay Kit following the manufacturer's protocol (GenScript, Piscataway, NJ) as described previously (Adjei-Fremah et al., 2016; Adjei-Fremah, 2017; Ekwemalor et al., 2018).

\subsection{Isolation of Total RNA and cDNA Synthesis}

Total RNA was isolated using Trizol according to the manufacturer's instructions (Sigma-Aldrich St. Louis, MO). RNA concentration and purity were assessed using a Nanodrop Spectrophotometer ND 1000 (Thermo Scientific Inc., Waltham, MA). RNA integrity purity was analyzed on an RNA 6000 Nano LabChip (Agilent Technologies, DE) following manufacturers protocol as described previously (Adjei-Fremah et al., 2016, 2018). Isolated total RNA (200ng/ $\mu \mathrm{l}$ ) was converted to complementary DNA (cDNA) from RNA using Retroscript kits (Ambion, Inc), following the manufacturer's instructions. Selected Primers used to validate RT ${ }^{2}$ Profiler Cow Innate \& Adaptive Immune Responses PCR Array (Table 1).

Table 1. Sequences of primers used for validation

\begin{tabular}{|c|c|c|c|c|}
\hline $\begin{array}{l}\text { Accession } \\
\text { Number }\end{array}$ & Gene & Primer & Sequence $5^{\prime}>3^{\prime}$ & Product size $(\mathrm{bp})$ \\
\hline \multirow{2}{*}{ NM_174197 } & \multirow{2}{*}{$T L R 2$} & Forward & ACGCCTTTGTGTCCTAC & \multirow{2}{*}{192} \\
\hline & & Reverse & CCGAAAGCACAAAGATGGTT & \\
\hline \multirow{2}{*}{ NM_173966 } & \multirow{2}{*}{$T N F \alpha$} & Forward & CTGCACTTCGGGGTAATCGG & \multirow{2}{*}{549} \\
\hline & & Reverse & CAGGGCGATGATCCCAAAGTA & \\
\hline \multirow{2}{*}{ NM_174088 } & \multirow{2}{*}{$I L-10$} & Forward & TGCTGGATGACTTTAAGGGTTACC & \multirow{2}{*}{186} \\
\hline & & Reverse & TCATTTCCGACAAGGCTTGG & \\
\hline \multirow{2}{*}{ NM_174008 } & \multirow{2}{*}{$C D 14$} & Forward & GACGACGATTTCCGTTGTGT & \multirow{2}{*}{600} \\
\hline & & Reverse & TGCTAGCGCTAGATATTGGA & \\
\hline \multirow{2}{*}{ AB098788 } & \multirow{2}{*}{$R P L P O$} & Forward & CAACCCTGAAGTGCTTGACAT & \multirow{2}{*}{564} \\
\hline & & Reverse & AGGCAGATGGATCAGCCA & \\
\hline \multirow{2}{*}{ XR_003033789 } & \multirow{2}{*}{$18 S$ rRNA } & Forward & TTCGATGGTAGTCGCTGTGC & \multirow{2}{*}{99} \\
\hline & & Reverse & TTGGATGTGGTAGCCGTTTCT & \\
\hline
\end{tabular}




\subsection{First Strand cDNA Synthesis and RT Profiler Array Analysis}

Purified Total RNA was reverse transcribed using First Strand cDNA Synthesis Kit for RT-qPCR (Qiagen), following manufacturer's instruction as described previously (Adjei-Fremah et al., 2017, 2018; Ekwemalor et al., 2016; Worku et al., 2016). Briefly, reaction mixture to eliminate genomic DNA, was incubated for $5 \mathrm{~min}$ at $42^{\circ} \mathrm{C}$, then place immediately on ice. To reverse transcribe, $10 \mu 1$ reverse-transcription mix was added to $10 \mu 1$ genomic DNA elimination mix. Mixture was incubated at $42^{\circ} \mathrm{C}$ for exactly $15 \mathrm{~min}$, then incubate at $95^{\circ} \mathrm{C}$ for $5 \mathrm{~min}$. Ninetyone $(91 \mu \mathrm{l}) \mathrm{RNase}$-free water was added to reaction.

$\mathrm{RT}^{2}$ Profiler Cow Innate \& Adaptive Immune Responses PCR Array containing primers for 84 tested and 5 housekeeping genes, and controls for RT reactions. Total volume of cDNA synthesized from First Strand Synthesis was used for preparation of reaction mixture. To each of 96 well-plates, $25 \mu 1$ reaction mixture comprised of $2 x$ $\mathrm{RT}^{2}$ SYBR Green Mastermix, cDNA synthesis reaction and RNase-free water (Qiagen) was added. Array plate was processed in CFX-96 (Bio-Rad), thermal cycling condition recommended by manufacturer (Qiagen), 10min $95^{\circ} \mathrm{C}, 15 \mathrm{~s} 95^{\circ} \mathrm{C}, 1 \mathrm{~min} 60^{\circ} \mathrm{C}$ repeat for 40 cycles.

Gene expression was normalized to housekeeping genes TYK2, ACTB, GAPDH, HPRT1, and TBP to determine fold change between treated and control samples using $2^{-\Delta \Delta C t}$ method (Livak \& Schmittgen, 2001).

\subsection{Total Protein Concentration}

Total protein concentration was measured in supernatant after treatment with galectin- 8 , in individual and pooled samples using Pierce BCA Assay kit (Rockford, IL), following manufacturer's instructions as described previously (Obanla et al., 2016; Adjei-Fremah et al., 2015; Hamilton et al., 2017; Karlton-Senaye et al., 2018).

\subsection{Quantification of Galectin-8 Secretion}

Bovine Galectin-8 Enzyme Linked-Immuno-Sorbent Assay (ELISA) kit (MyBiosource, Inc., San Diego, CA), was used to measure quantification of Galectin-8 Concentration in supernatant of treated and control samples. Details described elsewhere (Asiamah et al., 2018), briefly, $50 \mu \mathrm{L}$ of each standard and sample, and $100 \mu \mathrm{HRP}$ conjugate was added to appropriate wells. Wells were covered and incubated for an hour at $37^{\circ} \mathrm{C}$. The solution was discarded, and plate washed four times with 1X Wash Buffer. Fifty microlitters (50) $\mu$ l of chromogen A and chromogen B substrate was added to each well and incubated for 15 minutes at $37^{\circ} \mathrm{C}$, after which stop solution was added. Absorbance was measured at $450 \mathrm{~nm}$ using microplate reader (Bio Tek).

\subsection{Statistical Analysis}

One-way Analysis of variance (ANOVA) was performed on all variables using the statistical analysis software package SAS version 9.3 (SAS Institute, Cary, NC) to evaluate differences between treatment and control groups. P-value of $<0.05$ was considered to be significant.

\section{Results}

\subsection{Effect of rGalectin-8 Treatment on Neutrophil Count and on Cow Innate \& Adaptive Immune Response}

Treatment of bovine neutrophils with exogenous Galectin- 8 had no effect on the neutrophil count and viability (Table 2). There was no significant difference $(p>0.05)$ in the neutrophil cell count between treated and untreated groups. Individual animal variation was observed in the percentage of neutrophils. The average purity of neutrophil preparations was $94 \%$ or higher, as identified by stained smears.

Table 2. Analysis of bovine neutrophils count average percent viability following galectin- 8 treated and control

\begin{tabular}{llll}
\hline Parameter & Control & rGal-8 treated & $P$-value \\
\hline Total cell count (cells $/ \mathrm{ml})$ & $7.10 \times 10^{6} \pm$ & $6.19 \times 10^{6} \pm$ & NS \\
Total viable cells $($ cells $/ \mathrm{ml})$ & $1.07 \times 10^{6}$ & $1.12 \times 10^{6} \pm$ & NS \\
Neutrophils $(\%)$ & $94 \pm 96$ & $95 \pm 96$ & NS \\
\hline
\end{tabular}

Note. rGal-8 $=$ recombinant Galectin-8; NS $=P<0.05$.

RT $^{2}$ Profiler ${ }^{\mathrm{TM}}$ PCR Array Cow Innate \& Adaptive Immune Responses was observed at the level of mRNA transcription in recombinant Galectin-8 treated bovine neutrophils. The genes on the array consist of Innate and Adaptive immunity genes, Pattern Recognition Receptors (PRRs), Cytokines, Th1 and Th2 markers and Treg markers. Out of the 84 genes on the array, 81 genes were detected, 80 in the control group (Figure 1) and 81 in the treated group. Four genes were not detected in the control group IL18, IRAK1, MAPK1, and IRF7. Treatment with 
rGalectin-8 induced the expression of IRF7 in bovine neutrophils, this gene was not expressed in the control group. Treatment with rGalectin- 8 differentially affected the expression of 19 genes; 13 genes were up-regulated, 5 genes were down-regulated, and 61 genes remained unchanged or not significantly expressed. The up-regulated genes were FAS, CD40, CD86, IFNGR1, STAT1, CXCL8, TLR2, CD80, IL10, TNF, NLRP3, NFKB1, IFNG (Table 3). Down-regulated genes were TLR9, CD14, CCR6, TICAM1, TLR1 (Table 4). The highest fold changes were observed with cell surface receptor genes and cytokines.

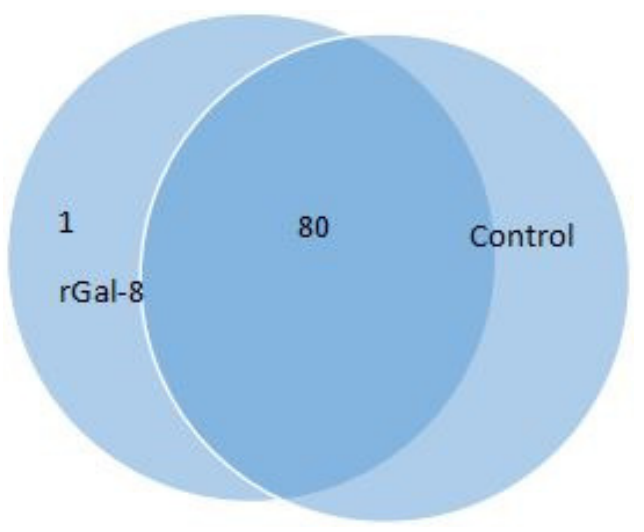

Figure 1. Venn diagram showing summary of 84 genes on the Innate \& Adaptive Immune Responses RT ${ }^{2}$ Profiler

PCR Array in response to treatment with rGalectin-8. Eighty genes were detected in the Galectin- 8 treated and control groups, one gene was induced by Galectin-8, three genes were not expressed in both groups.

Table 3. Up-regulated Cow Innate \& Adaptive Immune Responses PCR Array in response to rGalectin- 8 treatment

\begin{tabular}{|c|c|c|}
\hline Gene & Fold Change & Gene Function \\
\hline$F A S$ & 4.66 & Plays a central role in the physiological regulation of programmed cell death, adaptive immunity \\
\hline$C D 40$ & 3.77 & Co-stimulates T-cell proliferation and cytokine production, innate immunity \\
\hline$C D 86$ & 3.59 & Encodes a type I membrane protein that is a member of the immunoglobulin superfamily, Adaptive immunity \\
\hline IFNGRI & 3.58 & $\begin{array}{l}\text { Plays an essential role in the IFN-gamma pathway that is required for the cellular response to infectious } \\
\text { agents, Adaptive immunity }\end{array}$ \\
\hline STAT1 & 3.47 & Transcription factor that can induce a set of IFN- $\gamma$-regulated genes, Innate immunity \\
\hline$C X C L 8$ & 3.34 & $\begin{array}{l}\text { Neutrophil activation, released from several cell types in response to an inflammatory stimulus, Adaptive } \\
\text { immunity - cytokine }\end{array}$ \\
\hline$T L R 2$ & 3.15 & PRR, recognizes PAMPs, mediates the response to bacterial lipoproteins, innate immunity \\
\hline$C D 80$ & 3.07 & Costimulatory molecule known for its role in T-cell activation, Adaptive immunity \\
\hline IL10 & 3.05 & Prevents inflammatory and autoimmune diseases, Adaptive immunity \\
\hline$T N F$ & 2.74 & Pro-inflammatory cytokine, Adaptive immunity \\
\hline$N L R P 3$ & 2.53 & PRR, recognizes PAMPs, plays a crucial role in inflammation, Innate immunity \\
\hline$N F K B 1$ & 2.33 & Activated by various stimuli such as cytokines, bacteria or viruses, Innate immunity \\
\hline$I F N G$ & 2.0 & Antiviral activity, and immunoregulatory functions, Adaptive Immunity \\
\hline
\end{tabular}

Table 4. Down-regulated Cow Innate \& Adaptive Immune Responses PCR Array in response to rGalectin-8 treatment

\begin{tabular}{lll}
\hline Gene & Fold regulation & Gene Function \\
\hline TLR9 & -2.73 & PRR, alerts the immune system of viral and bacterial PAMPs, Innate immunity \\
$C D 14$ & -2.53 & Mediates the response to bacterial LPS, Innate immunity \\
$C C R 6$ & -2.31 & Chemotaxis of dendritic cells, immune responses to microbes, Th17 marker \\
TICAM1 & -1.96 & Involved in alerting against invading pathogens, Innate immunity \\
TLR1 & -1.94 & PRR recognize pathogen-associated molecular patterns (PAMPs), Innate immunity \\
\hline
\end{tabular}

Note. Gene functions are from GeneCards ${ }^{\circledR}$ (www.genecards.org) 
Following $\mathrm{RT}^{2}$ profiler array data analysis a set of genes was chosen for validation by RT-qPCR based on fold change and known effects of Galectin-8. Correlation between the RT ${ }^{2}$ profiler array and RT-qPCR results was performed, and the statistical significance of the correlation determined. The Livak's method was used to calculate transcript abundance. The selected genes were: TLR2, IL-10, TNF and CD14, primer sequence listed (Table 1). Bovine primers were designed using NCBI and primer 3 tool. Our results show up-regulation in expression of TLR2, IL-10 and TNF, and down-regulation in CD14 (Table 5). RPLPO and 18S rRNA were used as housekeeping genes to normalize expression.

Table 5. Validation of $\mathrm{RT}^{2}$ array results using Real Time-qPCR

\begin{tabular}{lll}
\hline & RT $^{2}$ Array & RT-qPCR \\
Gene & Fold change & Fold change \\
\hline TLR2 & 3.15 & 2.00 \\
IL-10 & 3.05 & 5.10 \\
TNF & 2.74 & 14.22 \\
CD14 & -2.53 & -2.77 \\
\hline
\end{tabular}

\subsection{Effect of Galectin-8 on Total Protein Concentration}

Total protein concentration was analyzed in treatment and control neutrophils. There was a significant difference in protein content of control compared to treated neutrophils $\mathrm{P}=0.036$ (Figure 2) in pooled and individual animal samples. There was variation in the total protein concentration level among the different animals used. Consequently, rGal-8 increased the total protein concentration in bovine neutrophils.

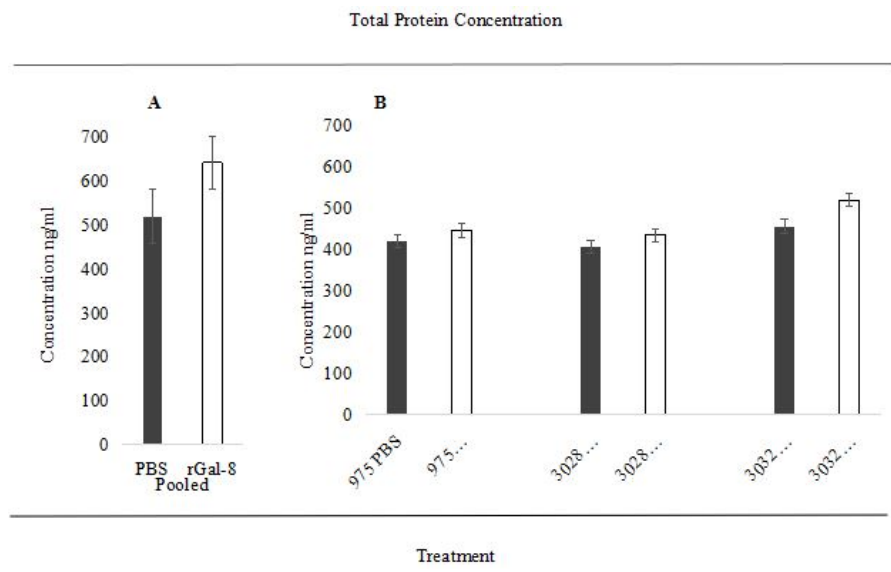

Figure 2. Total protein concentration in recombinant galectin- 8 treated and control neutrophils $(P=0.036)$

A. Total protein concentration in treated supernatant of pooled neutrophils $(\mathrm{n}=10)$. B. Total protein concentration in neutrophils of individual animals ( $\mathrm{n}=3$, Individual animal identification 975, 3028, 3032).

\subsection{Effect of rGalectin-8 Treatment on Galectin-8 Secretion}

Levels of secreted galectin- 8 were analyzed in both treatment and control groups. After treatment, the supernatant was used to detect levels of secreted galectin- 8 . Galectin- 8 is secreted in bovine neutrophils. There was no difference in the amount of secreted Galectin- $8(P=0.58)$ in treated and control groups (Figure 3$)$. 
Galectin-8 Secretion

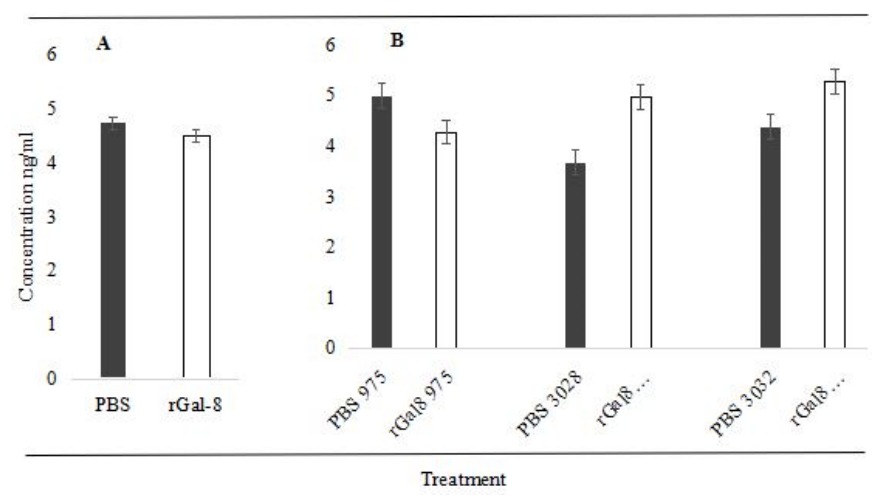

Figure 3. Secretion of Galectin-8 in bovine neutrophils following treatment with recombinant Galectin-8

Bovine specific Galectin-8 Enzyme-Linked Immunosorbent Assay (ELISA) on treated and control group ( $P=$ 0.36). A. Galectin- 8 secretion in pooled neutrophils $(\mathrm{n}=10)$, B. Galectin- 8 secretion in individual animals $(\mathrm{n}=3$, Individual animal identification 975, 3028, 3032). PBS=Phosphate Buffer Saline served as control.

\section{Discussion}

Galectins have been studied for their multifunctional roles. Galectin- 8 has been reported to be expressed in a variety of tissues. Previous studies conducted by our research group reported the expression of Galectin- 8 in bovine peripheral blood (Asiamah et al., 2017, 2018). Our current study investigated the effects of recombinant Galectin8 on secretion and expression of innate and adaptive immune response genes in bovine neutrophils.

Our RT ${ }^{2}$ Profiler ${ }^{\mathrm{TM}}$ PCR Array Cow Innate \& Adaptive Immune Responses result shows modulation in expression of neutrophils treated with exogenous Galectin-8. Dairy bovine neutrophils genes were expressed in the five control housekeeping genes ACTB, GAPDH, HPRT1, TBP, and YWHAZ. Three genes were not expressed at all in the control and treatment group, IL-18, MAPK1, and IRAK1. Treatment with rGal-8 induced the expression of Interferon regulatory factor 7 (IRF7). IRF is a member of the interferon regulatory transcription factor (IRF) family and plays a critical role in the innate immune response against DNA and RNA viruses (GeneCards, www.genecards.org). Furthermore, IRF7 is a crucial regulator of type I interferons (IFNs) against pathogenic infections, activation triggers signaling cascades from pathogen recognition receptors (PRRs) (Ning, Pagano, \& Barber, 2011). IFNG and IFNGR1 have increased fold change in response to Galectin- 8 stimulation. IFN function with receptors, one of the key receptors is the cargo receptor NDP52 which detects ubiquinatylated structures on bacteria (MacMicking, 2012). Galectin-8 has been shown to utilize the cargo receptor NDP52 to recruit autophagy to engulf lysosomal bacteria (Thurston et al., 2012). IRF7 activation in the presence of exogenous Galectin-8 demonstrates that Galectin-8 modulates the IFN-IRF7 system.

Previous studies have reported the expression of Toll-Like Receptors in cow neutrophils (Worku et al., 2016; AdjeiFremah et al., 2017, 2018). In our study treatment with recombinant Galectin-8 increased the expression of TLR2, and down-regulated the expression of TLR9. Toll-Like Receptor stimulation induced multiple signaling pathways. Some of these pathways include nuclear factor- $\mathrm{kB}$ (NF- $\mathrm{kB}$ ), mitogen-activated protein kinases (MAPKs) and typeI interferon (IFN) response (Akira et al., 2006). Treatment with recombinant Galectin-8 activated NF-kB1 and increased the expression of IL-10, CXCL8 and TNF cytokines. Previous studies have reported increase in expression of pro-inflammatory cytokines in human endothelial cells when treated with Galetin-8 (Cattaneo et al., 2014). The CD14 glycoprotein and receptor was found to be down regulated with treatment of Galectin- 8 . The interaction between recombinant Galectin- 8 and TLRs triggers the expression of several cytokines and may activate the innate immune system through the NF- $\mathrm{kB}$ pathway.

Gene expression analysis on the array showed Galectin- 8 increased the expression of FAS, a member of the TNFreceptor superfamily. Our results are consistent with previous research indicating that Jurkat $\mathrm{T}$ cells treated with galectin-8 had an increase in FAS expression (Norambuena et al., 2009). Furthermore, Norambuena et al. (2009) showed that Galectin- 8 exerted proapoptotic effects via activation of ERK1/2 in Jurkat T cells through FAS ligand. FAS is a part of the TNF superfamily, our result showed increased TNF expression in the presence of Galectin- 8 is consistent with previous findings. Treatment with Galectin- 8 increased the fold change in bovine neutrophils: analogous to our findings, mice splenocytes with exogenous galectins- 8 induced the expression of CD86 (Carabelli et al., 2017). 
Validation results using IL-10, TNF, TLR2 and CD14, showed comparable results to the array. When these primers were tested on individual animals, there were varying expressions of each gene (data not shown). Striking evidence has demonstrated that galectin- 8 can stimulate dendritic cells that secrete pro-inflammatory cytokines and stimulate antigen specific T-cells (Brinchmann et al., 2018; Carabelli et al., 2017).

In conclusion, this study provided preliminary evidence that exogenous recombinant Galectin- 8 is involved in modulation of the innate and adaptive immunity in bovine neutrophils. Binding of recombinant Galectin- 8 to TLRs through the NF- $\mathrm{kB}$ pathway may be important in bovine immune system. Further definition of the interaction between genes and pathways need further study.

\section{Acknowledgments}

The authors are grateful for the support of Mr. Corey Burgess at the North Carolina A\&T State University Dairy Unit; Dr. Hamid Ismail (Department of Animal Sciences). U.S. Department of Agriculture funded this research National Institute of Food and Agriculture Evans-Allen grant [grant number NC.X-300-5-16-120-1], and Integrative Bioinformatics for Investigating and Engineering Microbiomes (IBIEM) training fellowship.

\section{Conflict of interests}

The authors declare that there is no conflict of interests regarding the publication of this paper.

\section{References}

Adjei-Fremah, S. (2017). Molecular Effects of Cowpea Polyphenols on Mammalian Transcriptome, Proteome, and Microbiome (Doctoral dissertation, North Carolina Agricultural and Technical State University).

Adjei-Fremah, S., Asiamah, E. K., Ekwemalor, K., Jackai, L., Schimmel, K., \& Worku, M. (2016). Modulation of bovine Wnt signaling pathway genes by cowpea phenolic extract. Journal of Agricultural Science, 8(3), 21.

Adjei-Fremah, S., Asiamah, E. K., Ekwemalor, K., Osei, B., Ismail, H., Jackai, L. E., \& Worku, M. (2017). 055 The anti-inflammatory effect of cowpea polyphenol in bovine blood. Journal of Animal Science, 95(supplement4), 27-27.

Adjei-Fremah, S., Ekwemalor, K., Asiamah, E. K., Ismail, H., Ibrahim, S., \& Worku, M. (2018). Effect of probiotic supplementation on growth and global gene expression in dairy cows. Journal of Applied Animal Research, 46(1), 257-263.

Adjei-Fremah, S., Ekwemalor, K., Asiamah, E., Ismail, H., \& Worku, M. (2016). Transcriptional profiling of the effect of lipopolysaccharide (LPS) pretreatment in blood from probiotics-treated dairy cows. Genomics Data, $10,15-18$.

Adjei-Fremah, S., Jackai, L. E., \& Worku, M. (2015). Analysis of phenolic content and antioxidant properties of selected cowpea varieties tested in bovine peripheral blood. American Journal of Animal and Veterinary Sciences, 10(4), 235-245.

Adjei-Fremah, S., Jackai, L. E., Schimmel, K., \& Worku, M. (2018). Microarray analysis of the effect of Cowpea (Vigna unguiculata) phenolic extract in bovine peripheral blood. Journal of Applied Animal Research, 46(1), 100-106.

Akira, S., Uematsu, S., \& Takeuchi, O. (2006). Pathogen recognition and innate immunity. Cell, 124(4), 783-801.

Asiamah, E., Adjei-Fremah, S., Ekwemalor, K., Osei, B., Ismail, H., \& Worku, M. (2017). 338 The effect of stage of lactation and parturition on galectin expression in cow blood. Journal of Animal Science, 95(supplement4), 167-167.

Asiamah, E., Adjei-Fremah, S., Ekwemalor, K., Sordillo, L., \& Worku, M. (2018). Parity and Periparturient Period Affects Galectin Gene Expression in Holstein Cow Blood. Journal of Applied Biotechnology, 6(2), 20.

Asiamah, E., Ekwemalor, K., Adjei Fremah, S., Worku, M., \& Osei, B. (2018). PSVIII-41 Unique Signatures of Galectin Expression in Cow Blood Exposed to Microbial Cell Wall Antigens. Journal of Animal Science, 96(suppl_3), 33-33.

Bassel, L. L., \& Caswell, J. L. (2018). Bovine neutrophils in health and disease. Cell and Tissue Research, 371(3), 617-637.

Carabelli, J., Quattrocchi, V., D'Antuono, A., Zamorano, P., Tribulatti, M. V., \& Campetella, O. (2017). Galectin8 activates dendritic cells and stimulates antigen-specific immune response elicitation. J Leukoc Biol, 102(5), 1237-1247. 
Cattaneo, V., Tribulatti, M. V., Carabelli, J., Carestia, A., Schattner, M., \& Campetella, O. (2014). Galectin-8 elicits pro-inflammatory activities in the endothelium. Glycobiology, 24(10), 966-973.

Ekwemalor, K., Adjei-Fremah, S., Asiamah, E., Eluka-Okoludoh, E., Osei, B., \& Worku, M. (2018). Systemic expression of galectin genes in periparturient goats. Small Ruminant Research, 168, 60-68.

Ekwemalor, K., Adjei-Fremah, S., Asiamah, E., Ismail, H., \& Worku, M. (2016). 0167 Exposure of bovine blood to pathogen associated and non pathogen associated molecular patterns results in transcriptional activation. Journal of Animal Science, 94(suppl_5), 81-81.

Ekwemalor, K., Asiamah, E., Adjei-Fremah, S., \& Worku, M. (2016). Effect of a mushroom (Coriolus versicolor) based probiotic on goat health. Am J Anim Vet Sci, 11(3), 108-118.

Ekwemalor, K., Asiamah, E., Adjei-Fremah, S., Osei, B., Eluka-Okoludoh, E., Mulakala, B., \& Worku, M. (2018). PSVI-32 Pathogen-associated molecular patterns induce differential galectin-3 activation in Goat blood. Journal of Animal Science, 96(suppl_3), 464-464.

Eluka-Okoludoh, E., Asiamah, E., Ekwemalor, K., Mulakala, B., Adjei-Fremah, S., \& Worku, M. (2018). PSVIII37 Modulation of innate and adaptive immune response genes in bovine neutrophil by Galectin-8. Journal of Animal Science, 96(suppl_3), 31-32.

GeneCards - the human gene database. Retrieved from http://www.genecards.org

Hadari, Y. R., Paz, K., Dekel, R., Mestrovic, T., Accili, D., \& Zick, Y. (1995). Galectin-8. A new rat lectin, related to galectin-4. J Biol Chem, 270(7), 3447-3453.

Hamilton, A. M., Worku, M., Thompson, H. L., \& Adjei-Fremah, S. (2017). 066 Goat parasite incidence and host resilience in North Carolina during the fall season. Journal of Animal Science, 95(supplement4), 33-33.

Karlton-Senaye, B., Adjei-Fremah, S., Worku, M., \& Williams, L. (2018). Synergistic Effect of Polysaccharide Gums and Antimicrobial Agents on Susceptibility and Protein Expression of Select Pathogenic Microorganisms in Milk. Journal of Food Research, 7(2), 35.

Livak, K. J., \& Schmittgen, T. D. (2001). Analysis of relative gene expression data using real-time quantitative PCR and the 2(T)(-Delta Delta C) method. Methods, 25(4), 402-408.

MacMicking, J. D. (2012). Interferon-inducible effector mechanisms in cell-autonomous immunity. Nature Reviews Immunology, 12(5), 367.

Medzhitov, R., \& Janeway, C. Jr. (2000). Innate immunity. N Engl J Med, 343(5), 338-344.

Mulakala, B., Eluka-Okoludoh, E., Adjei-Fremah, S., Asiamah, E., Ekwemalor, K., Ismail, H., ... \& Worku, M. (2018). PSVIII-29 Galectin 9 secretion in cow milk a marker for homostasis and health. Journal of Animal Science, 96(suppl_3), 30-31.

Ning, S., Pagano, J. S., \& Barber, G. N. (2011). IRF7: Activation, regulation, modification and function. Genes Immun, 12(6), 399-414.

Nishi, N., Shoji, H., Seki, M., Itoh, A., Miyanaka, H., Yuube, K., ..., \& Nakamura, T. (2003). Galectin-8 modulates neutrophil function via interaction with integrin alphaM. Glycobiology, 13(11), 755-763.

Norambuena, A., Metz, C., Vicuna, L., Silva, A., Pardo, E., Oyanadel, C., ..., \& Soza, A. (2009). Galectin-8 induces apoptosis in Jurkat $\mathrm{T}$ cells by phosphatidic acid-mediated ERK1/2 activation supported by protein kinase A down-regulation. $J$ Biol Chem, 284(19), 12670-12679.

Obanla, T., Adjei-Fremah, S., Gyawali, R., Zimmerman, T., Worku, M., \& Ibrahim, S. A. (2016). Effects of Long Term Exposure to Aspirin on Growth, Functionality and Protein Profile of Lactobacillus rhamnosus (LGG)(ATCC 53103). Journal of Food Research, 5(4), 46.

Osei, B., Worku, M., Adjei-Fremah, S., Asiamah, E., Ekwemalor, K., \& Ismail, H. (2017). 040 Expression galectins in sheep blood during the periparturient period. Journal of Animal Science, 95(supplement4), 2020.

Paape, M. J., Bannerman, D. D., Zhao, X., \& Lee, J. W. (2003). The bovine neutrophil: Structure and function in blood and milk. Vet Res, 34(5), 597-627.

Panda, S. K., Facchinetti, V., Voynova, E., Hanabuchi, S., Karnell, J. L., Hanna, R. N., ..., \& Liu, Y.-J. (2018). Galectin-9 inhibits TLR7-mediated autoimmunity in murine lupus models. The Journal of clinical investigation, 128(5). 
Rabinovich, G. A., \& Gruppi, A. (2005). Galectins as immunoregulators during infectious processes: from microbial invasion to the resolution of the disease. Parasite Immunology, 27(4), 103-114.

Stelzer, G., Rosen, R., Plaschkes, I., Zimmerman, S., ..., \& Lancet, D. (2016). The GeneCards Suite: From Gene Data Mining to Disease Genome Sequence Analysis. Current Protocols in Bioinformatics, 54, 1.30 .1 1.30.33.

Tribulatti, M. V., Cattaneo, V., Hellman, U., Mucci, J., \& Campetella, O. (2009). Galectin-8 provides costimulatory and proliferative signals to T lymphocytes. J Leukoc Biol, 86(2), 371-380.

Troncoso, M. F., Ferragut, F., Bacigalupo, M. L., Cardenas Delgado, V. M., Nugnes, L. G., Gentilini, L., ..., \& Elola, M. T. (2014). Galectin-8: A matricellular lectin with key roles in angiogenesis. Glycobiology, 24(10), 907-914.

Ungerer, C., Quade-Lyssy, P., Radeke, H. H., Henschler, R., Konigs, C., Kohl, U., ..., \& Schuttrumpf, J. (2014). Galectin-9 Is a Suppressor of T and B Cells and Predicts the Immune Modulatory Potential of Mesenchymal Stromal Cell Preparations. Stem Cells and Development, 23(7), 755-766.

Vasta, G. R., Ahmed, H., Fink, N. E., Elola, M. T., Marsh, A. G., Snowden, A., \& Odom, E. W. (1994). Animal Lectins as Self/Non-Self Recognition Molecules - Biochemical and Genetic Approaches to Understanding Their Biological Roles and Evolution. Primordial Immunity: Foundations for the Vertebrate Immune System, 712, 55-73.

Worku, M., Abdalla, A., Adjei-Fremah, S., \& Ismail, H. (2016). The impact of diet on expression of genes involved in innate immunity in goat blood. Journal of Agricultural Science, 8(3), 1.

Worku, M., Adjei-Fremah, S., Ekwemalor, K., Asiamah, E., \& Ismail, H. (2016). 0130 Growth and transcriptional profile analysis following oral probiotic supplementation in dairy cows. Journal of Animal Science, 94(supplement5), 61-61.

Worku, M., Adjei-Fremah, S., Whitley, N., \& Jackai, L. (2017). Effect of Cowpea (Vigna unguiculata) Pasture Grazing on Growth, Gastrointestinal Parasite Infection and Immune Response Biomarkers of Goat. Journal of Agricultural Science, 10(1), 27.

\section{Copyrights}

Copyright for this article is retained by the author(s), with first publication rights granted to the journal.

This is an open-access article distributed under the terms and conditions of the Creative Commons Attribution license (http://creativecommons.org/licenses/by/4.0/). 